\title{
ФОТОНИКА В РОССИИ: СОСТОЯНИЕ И ЗАДАЧИ.
}

\section{ЧАCTЬ 1}

\author{
И. Б. Ковш, президент Лазерной ассощиащии
}

\begin{abstract}
Развитие лазерной техники привело к созданию фотоники как отдельной высокотехнологичной промышленной отрасли. Эксперты связывают с ней возможности решения многих проблем, стоящих перед человечеством в области информационного обеспечения, промышленного производства, энергетики, здравоохранения, охраны окружающей среды, обеспечения безопасности. Львиная доля гражданской продукции фотоники, предлагаемой российскими производителями, - это изделия малых предприятий. Именно они формируют внутренний рынок. В первой части обзора рассмотрена структура отрасли фотоники в России, современное состояние и проблемы, сдерживающие ее развитие, которые характерны для всего отечественного хай-тека.
\end{abstract}

Статья поступила в редакцию 20.02.2019. Статья принята к публикации 20.03.2019.

\section{НАУЧНО-ТЕХНИЧЕСКАЯ ОБЛАСТЬ И ОТРАСЛЬ}

В последние 10-15 лет в нашу жизнь вошел термин "фотоника", который, как часто приходится убеждаться, различные группы специалистов используют для обозначения разных вещей. Поэтому начнем с определения. Формирование фотоники как отдельной научно-технической области, а затем и отдельной отрасли высокотехнологичной промышленности было обусловлено развитием лазерной техники. Использование энергии в форме лазерного излучения революционным образом обогатило технические возможности человечества. Когерентность этого излучения и обусловленная этим возможность его концентрации в пространстве и в спектральном диапазоне, преобразования с высокой эффективностью по частоте, широкое разнообразие режимов излучения: от непрерывного до ультракоротких импульсов - и механизмов воздействия на вещество: от простого нагрева до селективного возбуждения квантовых систем - позволили создать большое количество принципиально новых методов и технологий, которые оказались весьма перспективными для многих практических применений. Для реализации этих перспектив потребовалось совершенствование как самих источников излучения, так и средств его транспортировки,

Примечание редактора. Статья публикуется с разрешения издания Лазерной ассоциации "Лазер-Информ". Впервые статья опубликована в сокращенном виде в "Лазер-Информ", 2019,№ 2, стр 1-16. управления его параметрами и контроля этих параметров, потребовалось детальное исследование взаимодействия лазерного излучения с веществом - так формировалась новая научнотехническая область, которую сегодня называют фотоникой (рис. 1). Методы и технологии, созданные в этой области, нашли широчайшее практическое применение. По своей роли в развитии цивилизации освоение лазерной техники равнозначно электрификации в начале XX века. Области наиболее активного использования фотоники сегодня:

- обработка материалов в промышленности;

- бесконтактные измерения и диагностика (техническое зрение);

- запись, хранение, обработка и передача информации, связь;

- диагностика и лечение заболеваний человека и животных;

- задание направлений и управление движением;

- визуализация информации, дисплеи, световые шоу;

- скрытая маркировка документов и изделий, распознавание изображений;

- биостимуляция в растениеводстве и животноводстве;

- дистанционное зондирование, картирование рельефов;

- энергетика;

- исследовательское оборудование для естественных наук; 
- обеспечение безопасности людей и объектов;

- военные применения.

В ближайшей перспективе обеспечение управления беспилотными автомобилями, борьба с космическим мусором, квантовые технологии в информатике и др. Вообще говоря, трудно назвать область человеческой деятельности, где бы сегодня не использовалась фотоника. Термин "фотоника" и соответствующую научно-техническую область можно определить следующим образом: фотоника - это совокупность информационных, коммуникационных, энергетических и др. технологий, базирующихся на эффективной передаче энергии и/или информации потоком одинаковых или почти одинаковых фотонов. К фотонике относятся также процессы генерации, транспортировки и диагностики таких потоков, управления ими и их взаимодействия с веществом. $\mathrm{K}$ фотонике относят и фотовольтаику, в которой узость энергетического спектра фотонов определяется не их источником, а полосой поглощения приемника. "Рядом" с фотоникой находятся оптика и светотехника - научно-технические области, охватывающие процессы, методы и оборудование, улучшающие возможность видеть, получать с помощью видимого света зрительную информацию; оптика - за счет усиления зрения в нужном направлении, светотехника за счет освещения наблюдаемого объекта, улучшение его видности, возможности видеть его детали глазами (рис. 2). Напомним при этом, что "оптика" в переводе с греческого означает "наука о зрении".

\section{РОЛЬ ФОТОНИКИ В ЭКОНОМИКЕ. МИРОВЫЕ ТЕНДЕНЦИИ}

Именно с фотоникой связывают сегодня западные эксперты возможность решения многих стоящих перед человечеством проблем в области информационного обеспечения, промышленного производства, энергетики, здравоохранения, охраны окружающей среды, обеспечения безопасности.

Об экономическом эффекте, обеспечиваемом фотоникой, можно судить по таким примерам:

Системы оптической связи (по лазерному лучу, распространяющемся в световолокне) и оптоин-

форматики (запись, обработка, хранение и воспроизведение информации с помощью лазерного луча) радикально увеличили скорость обработки и передачи больших массивов информации, сделали возможными Интернет, телекоммуникации и обеспечили переход к информационному обществу и цифровизации экономики. Экономический эффект измеряется здесь триллионами долларов.

В микроэлектронике производство чипов без технологий фотоники (литография, контроль поверхностных слоев и структуры поверхности и др.) практически невозможно, и роль этих технологий растет с уменьшением минимального размера элемента на чипе. Согласно дан ${ }^{-}$ ным 2000-2003 годов, выпуск специализированного производственного оборудования фотоники на 1 млрд долларов обеспечивал производство чипов на 155 млрд долларов и на их базе - инновационной продукции для конечного пользователя на 1,2 трлн долл (компьютерная техника, мобильные телефоны, цифровые камеры и т.д.). Сегодня зависимость микроэлектроники от технологий фотоники стала абсолютной.

На современное освещение тратится 10-15\% всего мирового производства электроэнергии, в денежном выражении - около 325 млрд долларов в год. В ближайшие 20 лет этот объем должен увеличиться вдвое - если не будут приняты радикальные меры, не произойдет переход к новым системам освещения. Освоение светодиодной техники позволяет снизить энергозатраты на освещение не менее, чем на 30\% уже к 2020 году, а к 2025 году - на 50\%. Эти оценки сделаны без учета затрат на борьбу с загрязнениями, обусловленными производством электроэнергии и утилизацией массово используемых сегодня светильников, учет таких затрат еще более повышает экономическую эффективность освоения современной фотоники в освещении. 
Использование возможности эффективной передачи энергии и/или информации потоком одинаковых (или почти одинаковых) фотонов - фотоника

\section{Продукция фотоники}

Лазерное технологическое

оборудование, включая лаз.

оборудование для полиграфии

Аппаратура оптической связи

Аппаратура световых шоу, дисплеи

Лазерно-оптическое

оборудование для технических

измерений и диагностики

Оптические системы записи,

хранения, обработки и

воспроизведения информации

\begin{tabular}{ll} 
воспроизведения информации & навигационную аппаратуру \\
\hline Солнечные батареи
\end{tabular}

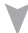

\section{Элементная база фотоники}

Источники лазерного излучения и светодиоды, их комплектующие

Оптические элементы и узлы для управления лазерным излучением по спектру, поляризации, форме и длительности импульса

Фотовольтаические преобразователи солнечной энергии

Детекторы и приемники

лазерного излучения

Аппаратура контроля параметров лазерного излучения, включая оптические стандарты
Оптические сенсоры, системы контроля состояния и охраны объектов

\section{Оборонная фотоника}

Лазерные системы визуализации направлений и плоскостей, лазерные визиры, целеуказатели, имитаторы стрельбы

Лазерно-оптические и оптико-электронные информационные системы, включая лазерную навигационную аппаратуру

Элементы и схемь оптоэлектроники

Устройства защиты от лазерного излучения

Оптические элементы и узлы для управления положением в пр-ве и транспортировки лазерного излучения, включая адаптивную оптику, микрооптику и волоконнооптические компоненты

Узлы и затворы для управления временными режимами работы и энергетикой источников излучения

Обеспечение возможности видеть, получать зрительную информацию оптика и светотехника

За счет усиления зрения в нужном направлении

\section{Продукция оптики}

\section{Очки, лупы}

Оптические

микроскопы

Телескопы

Бинокли, зрительные трубы, перископы

Оптические прицелы, визиры

Геодезические

и навигационные приборы

Фото- и кинообъективы

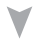

\section{Элементная база}

оптики

Оптические элементы пластинки, призмы, линзы, зеркала и др.

\section{Системы}

позиционирования и фиксации оптических элементов и узлов

Фотометрическое и колориметрическое оборудование
За счет улучшения видности объектов

\section{ortuчeckиe cTaндарты}

\section{$Y$}

Специфические материалы, используемые в фотонике, оптике и светотехнике, и оборудование для их изготовления и обработки

\begin{tabular}{|c|c|c|}
\hline Оптические стекла, ситаллы & Оптические кристаллы и оптическая & Оборудование для варки стекла, \\
\hline \multirow{2}{*}{$\begin{array}{l}\text { Полупроводниковые материалы для } \\
\text { изготовления лазеров, светодиодов, } \\
\text { детекторов света и др. }\end{array}$} & \multirow{3}{*}{$\begin{array}{l}\text { - } \text { для пропускания и отражения света } \\
\text { - для изготовления активных элементов } \\
\text { лазеров } \\
\text { - } \text { для спектрального преобразования } \\
\text { излучения }\end{array}$} & $\begin{array}{l}\text { выращивания кристаллов, напыления } \\
\text { покрытий и др. }\end{array}$ \\
\hline & & Контрольно-диагностическая аппаратура \\
\hline Материалы для оптических покрытий & & Фоточувствительные материалы \\
\hline Материалы для изготовления оптоволо & & Люминофоры \\
\hline
\end{tabular}


Внедрение лазерно-оптических технологий ранней диагностики заболеваний и малоинвазивного лечения позволяет заметно сократить продолжительность госпитализации больных, увеличить эффективность лекарственного лечения. Согласно оценкам японских экспертов, это сокращает "медицинские" расходы их страны на $20 \%$, годовой экономический эффект в мире - не менее 400 млрд долларов (затраты на здравоохранение только в США в 2004 году составили 1,8 трлн долл., а в Германии - 250 млрд долл.). Неудивительно, что мировой рынок медицинской фотоники еще в 2010 году составил 20,4 млрд долл. а в 2016 - уже более 40 млрд долл.

Освоение технологий фотоники по своей значимости для цивилизации сравнивают с электрификацией в начале XX века. Развитые государства предпринимают активные усилия для ускоренного развития фотоники как отрасли хайтека. Примером может служить Евросоюз, где фотоника признана одной из 6 ключевых "обеспечивающих" технологий сегодняшнего дня ("key enabling technologies»). В Европейской комиссии еще в начале 2000-х было создано специальное подразделение для координации усилий стран ЕС в части развития фотоники, организована Технологическая платформа ЕС "Photonics21", на поддержку программ и проектов, рекомендованных этой Платформой (НИОКР и создание необходимойинфраструктуры), ежегодно из бюджета ЕС выделяется около 100 млн евро (финансирование фотоники было предусмотрено отдельной строкой в 7-й Рамочной программе Евросоюза и продолжается в рамках Стратегии «HORIZON-2020»).

B результате средние темпы роста объемов производства фотоники в ЕС в последние 10 лет составляют 8\% - несмотря на рецессию экономики - а годовой объем производства продукции фотоники в ЕС еще в 2015 году достиг 69 млрд евро. В этой отрасли в Евросоюзе работают около 400 тыс. чел., больше всего - в Германии, Великобритании, Франции, Нидерландах, Италии и Швейцарии. От технологий фотоники непосредственно зависит 25\% всей европейской экономики и 10\% всех работающих (около 30 млн рабочих мест).

В США фотоника признана технологией первостепенной необходимости для страны ("essential for our nation"), в ее развитие вкладываются весьма значительные средства (например, только на НИОКР в 2010 году - около 540 млн долл. через агентство DARPA и 960 млн долл.- в виде грантов Национального института здоровья), что позволяет США сохранять лидирующие позиции в части исследований и разработок по фотонике и ее применениям. Сегодняшнюю роль фотоники в США иллюстрирует такой, например, факт.

Среди 50 важнейших американских изобретений 2011 года, отобранных экспертами США, 12 были основаны на лазерно-оптических технологиях. В 2015 году доля США в мировом объеме производства продукции фотоники составляла около $13 \%$, уступая ЕС, Китаю и Японии. Сейчас поставлена задача вернуть в США производство многих видов продукции фотоники. В 2012 году после публикации Национальным исследовательским советом доклада по развитию фотоники и оптики в США был начат процесс запуска Национальной инициативы в области фотоники (National Photonics Initiative). В частности, в 2015 году под эгидой Министерства обороны был создан специализированный Институт интегральной фотоники для инноваций в области производственных технологий (Integrated Photonics Institute for Manufacturing Innovation - IP-IMI) в рамках национальной сети промышленных инноваций (National Network for Manufacturing Innovation). Институт уже получил серьезное финансирование - из федерального бюджета было выделено 110 млн долл., а промышленность софинансирует его работу в размере 503 млн долл.

В Китае действует специальная государственная целевая программа, приведшая к созданию за 12 лет более 5 тыс. предприятий лазерно-оптической специализации и росту объема производства продукции фотоники в КНР в среднем на 25-30\% в год в 2000-2017 годы (в 2015 году этот объем составил уже около 120 млрд долл.). В результате Китай стал абсолютным мировым лидером по объему производства фотоники. Главными направлениями развития лазернооптических технологий здесь являются телекоммуникации (в частности, на Китай приходится сегодня 60\% мирового объема производства оптоволокна), медицинские технологии (80\% всех медицинских учреждений КНР с числом пациентов более 200 уже имеют специальные отделения или участки лазерной диагностики и/или лечения), новые производственные технологии. Кроме того, в Китае очень мощно развивается оборонная фотоника. Правительство КНР приняло решение организовать в 2015-2025 годы “золотую декаду для лазерной индустрии". Это стало частью дорожной карты "Made in China 


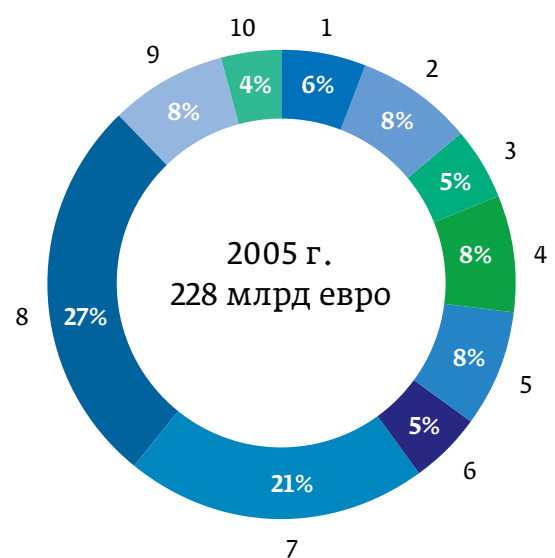

1. Производственное оборудование

2. Измерения и автоматизированное техническое зрение

3. Оптические компоненты и системы

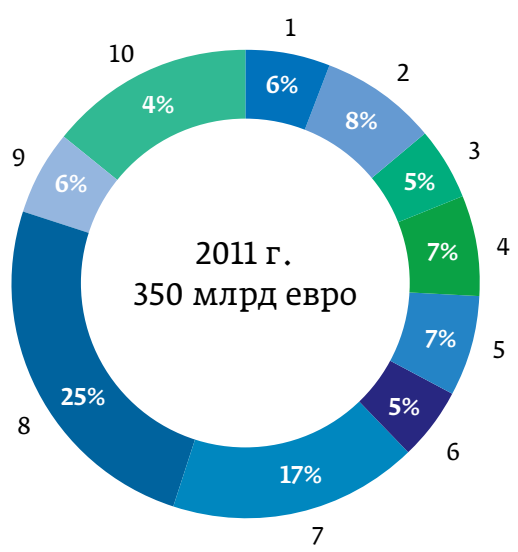

4. Оборудование для обеспечения безопасности и обороны

5. Оборудование для медицины и наук о жизни 6. Оборудование для связи

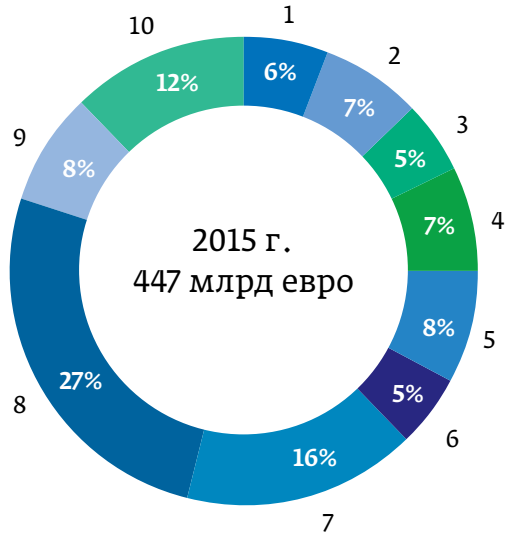

7. Информационное оборудование

8. Дисплеи

9. Источники света

10. Фотовольтаика

Puc. 3. Ключевые данные по мировому рынку фотоники. Источник: евразийская технологическая платформа Photonics21

2025", которая должна сделать Китай в течение 10 лет мировым промышленным лидером. На 12-м международном форуме OVC EXPO (Ухань, КНР) в ноябре 2015 года было четко заявлено, что лазер как высокоэффективный инструмент для обработки материалов будет играть важнейшую роль в превращении Китая в мирового промышленного гиганта в предстоящие 10 лет.

К числу стран, целенаправленно и весьма активно развивающих свою фотонику, помимо Китая, лидеров ЕС и США, относятся также Япония, Южная Корея, Тайвань, Канада, Малайзия. Мировой объем производства продукции фотоники быстро растет (рис. 3). Отметим при этом практическое совпадение средних темпов роста производства продукции фотоники - приборы, аппараты, технологические установки и т.п.- и производства источников лазерного излучение (рис. 4), что подтверждает тот факт, что фотоника базируется именно на лазерах.

Фотоника, по мнению экспертов Еврокомиссии, стала сегодня драйвером современной технологически развитой промышленности, одним из главных локомотивов инновационного развития мировой экономики. Общая статистика рынков хай-тека подтверждает это заключение (рис. 5), и неудивительно, что как отрасль она имеет мощную поддержку в развитых странах (рис. 6). Следует подчеркнуть, что использование энергии лазерного луча становится системообразующей технологией, все более определяющей техническую инфраструктуру, которую использует человечество. Единственным ана-

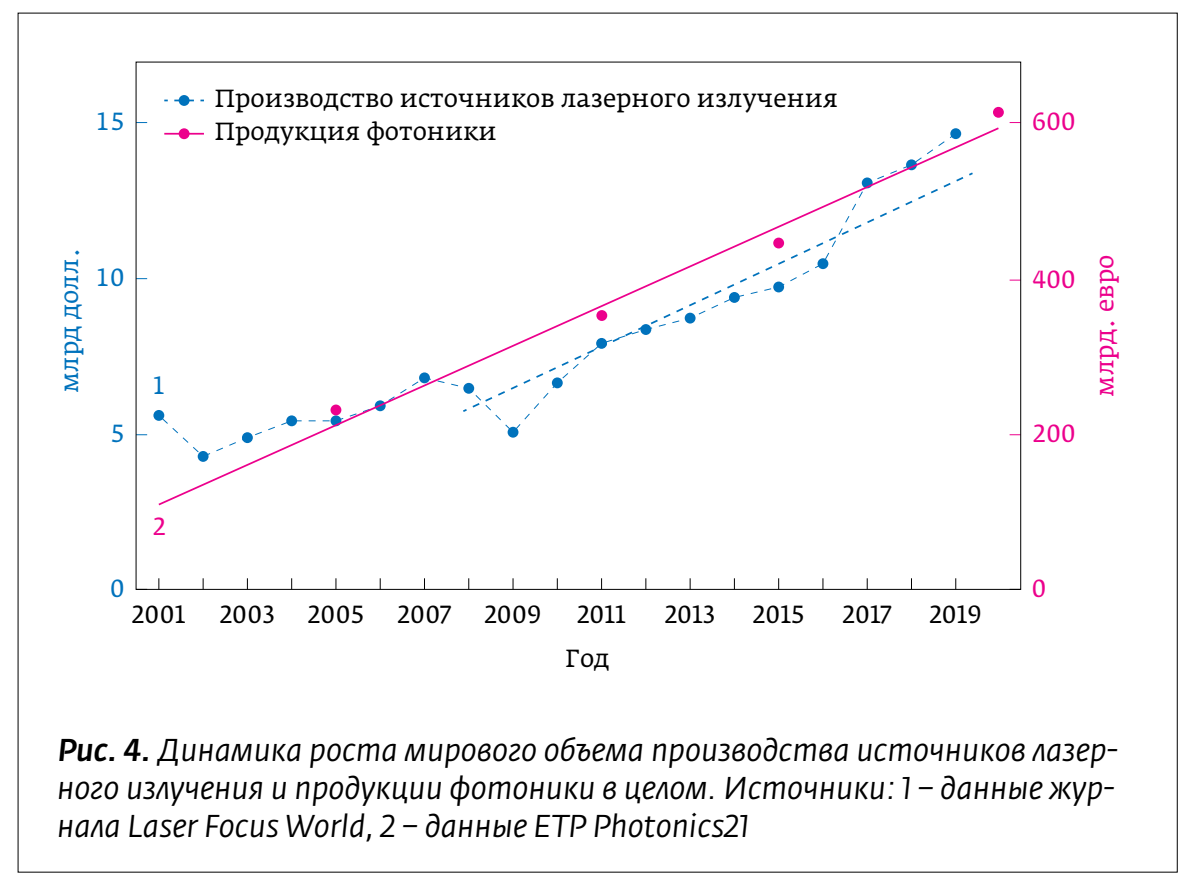


Оценка 2015 г. объемов мирового рынка для 6 областей технологий, признанных в Евросоюзе ключевыми (Key Enabling Technologies)

Фотоника, 355 млрд евро

Микро- и наноэлектроника, 222 млрд евро

Новые производственные технологии, 151 млрд евро

Новые материалы, 111 млрд евро

Биотехнологии, 92 млрд евро

Нанотехнологии, 20 млрд евро

Фотоника в ЕС в 2014 г.:

- 5 тыс. компаний

- 377 тыс. рабочих мест

- 60 млрд евро объем производства (160 тыс. евро / чел.год)

Puc. 5. Экономическое значение фотоники. Источник: Европейский консорциум индустрии фотоники (ЕРІC)

логом является использование электрической энергии.

\section{РОССИЙСКАЯ ФОТОНИКА - \\ ОРГАНИЗАЦИИ И ПРОДУКЦИЯ, ВНУТРИОТРАСЛЕВЫЕ СТРУКТУРЫ}

Наша страна, бывшая одним из двух пионеров в создании квантовой электроники и лазерной техники, а также изучении вопросов распространения лазерного излучения и его взаимодействия с веществом, имеет мощный научный потенциал в части фотоники, большой опыт в проведении разработок в этой области и большое число предприятий и организаций, активно работающих сегодня по тематике фотоники, ведущих исследования и создающих оборудование и технологии. В общей сложности в России в 2018 году насчитывалось около 840 таких организаций, в т.ч. около 100 академических институтов, около 140 ВУЗов и научно-технических центров при ВУЗах, 115 отраслевых НИИ, КБ и НПО, более 70 производственных объединений и крупных предприятий, 75 медицинских учреждений (включая медицинские ВУЗы) и около 340 малых предприятий. В это число не входят центры предоставления услуг по лазерной обработке материалов («jobshops»), лазерной косметологии и т. п. - таких в России более 500. По территории страны разработчики технологий и оборудования фотоники распределены весьма неравномерно. Центрами максимальной концентрации организаций и предприятий отрасли являются
Опережающий рост (темпы роста в 2011-2020 гг. минимум в 1,5 раза выше темпов роста ВВП)

Появление приоритетов с еще более быстрым ростом:

- производственные технологии (реиндустриализация в развитых странах);

- медицинские применения, биофотоника (старение населения, необходимость улучшения медобслуживания);

- светодиодное освещение (урбанизация в Азии, необходимость энергосбережения)

Резкое увеличение роли Китая в мировом производстве продукции фотоники (по объему производства вышел на 1 место в мире)

Активное государственное управление развитием фотоники (финансирование НИОКР, госзаказ, налоговая политика, поддержка экспорта, поддержка отечественного производителя, стимулирование инвестиций в отрасль и др.) в странах - лидерах по производству и освоению фотоники

Рuс. 6. Тенденции мирового рынка фотоники

(по числу юрлиц) Москва (40\%), С. Петербург (14\%), Новосибирск (6\%), Московская область (5\%) и Поволжье (Нижегородская, Самарская, Саратовская области и Татарстан - вместе около 8\%), а в общей сложности такие предприятия и организации имеются в 57 регионах страны.

При этом следует подчеркнуть, что фотоника в большинстве случаев не является единственной специализацией для российских исследовательских институтов и крупных предприятий. Среди них лишь участники Оптического холдинга "Швабе" ГК "Ростех" и несколько частных компаний могут быть отнесены к числу чисто "лазерно-оптических" организаций. Только для малых предприятий, работающих в области фотоники, эта тематика практически всегда является единственной профильной. В некотором смысле российская фотоника - это отрасль, состоящая в значительной части из малых предприятий.

Росстат не ведет какого-либо учета в части фотоники, поэтому все нижеследующие оценки это данные опросов, проведенных Лазерной ассоциацией. Около 230 российских организаций являются производителями лазерной, оптической и оптоэлектронной продукции (рис. 7). Более $60 \%$ таких организаций - малые предприятия. Общий объем производства продукции фотоники в России за 2017 год составил более 74 млрд руб. Основной вклад в этот объем (примерно 84\%) внесли большие предприятия (с числом занятых в производстве фотоники более 100 человек). На малые предприятия пришлось около 


\section{Производятся практически все известные виды продукции фотоники}

Источники лазерного излучения Фотоника в связи и обработке информации Лазерное технологическое оборудование Измерительно-диагностическая техника Лазерная медицинская аппаратура Приборы контроля лазерного излучения Лазерная оптика

\author{
1,3 тыс. моделей \\ $\sim 1,1$ тыс. моделей \\ -450 моделей \\ -290 моделей \\ -300 моделей \\ -100 моделей \\ тысячи типоразмеров оптических компонентов (около сотни материалов), \\ а также десятки моделей затворов, модуляторов, сканаторов и др.
}

Число отечественных организаций-производителей

\begin{tabular}{|c|c|c|c|c|c|c|}
\hline $\begin{array}{l}\text { Источники } \\
\text { излучения }\end{array}$ & $\begin{array}{l}\text { Технологические } \\
\text { установки }\end{array}$ & $\begin{array}{l}\text { Измерения } \\
\text { и диагностика }\end{array}$ & $\begin{array}{l}\text { Медицинская } \\
\text { аппаратура }\end{array}$ & $\begin{array}{l}\text { Лазерная } \\
\text { оптика }\end{array}$ & $\begin{array}{l}\text { Приборы } \\
\text { контроля ли }\end{array}$ & $\begin{array}{l}\text { Оптическая связь } \\
\text { и передача информации }\end{array}$ \\
\hline $\begin{array}{l}51, \text { в т. ч. } \\
\text { Россия - } 46 \\
\text { Беларусь - } 5\end{array}$ & $\begin{array}{l}49, \text { в т. ч. } \\
\text { Россия - } 45 \\
\text { Беларусь - } 4\end{array}$ & $\begin{array}{l}53, \text { в т. ч. } \\
\text { Россия - } 48 \\
\text { Беларусь - } 5\end{array}$ & $\begin{array}{l}\text { 53, в т. ч. } \\
\text { Россия - } 45 \\
\text { Беларусь - } 6 \\
\text { Украина - } 2\end{array}$ & $\begin{array}{l}63, \text { в т. ч. } \\
\text { Россия - } 56 \\
\text { Беларусь- } 6 \\
\text { Армения - } 1\end{array}$ & $\begin{array}{l}\text { 12, в т. ч. } \\
\text { Россия - } 10 \\
\text { Беларусь - } 2\end{array}$ & $\begin{array}{l}30, \text { в т. ч. } \\
\text { Россия - } 29 \\
\text { Беларусь - } 1\end{array}$ \\
\hline
\end{tabular}

Puc. 7. Выпуск продукции фотоники в СНГ в 2018 году

14\%, остальное - результат производственной деятельности отдельных НИИ, КБ и университетских НТЦ, которые тоже выпускают продукцию фотоники. В России находится также отделение одной из крупнейших компаний мировой лазерной индустрии - американской корпорации IPG. Это НТО "ИРЭ-Полюс" в подмосковном Фрязино с числом работающих около 1,8 тысяч человек и многомиллионными оборотами. Их данные в нижеследующих оценках объемов производства и экспорта российской фотоники не учитывались.

Производством продукции фотоники на российских предприятиях занимаются в общей сложности около 38,5 тысяч человек, средняя выработка на человека в год составила в 2017 году 2 млн руб., что существенно меньше, чем в европейской фотонике (в Западной Европе средняя выработка на предприятиях лазерно-оптической специализации уже в 2014 году была равна 160 тыс. евро/чел). Однако на целом ряде отечественных малых и средних предприятий лазерно-оптической специализации выработка была весьма близка к европейскому уровню, а на некоторых и заметно превосходила его (до 12-15 млн руб./чел.год). Доля экспорта в общем объеме продаж продукции фотоники российского производства составила в 2017 году 20\%, в т. ч. у малых предприятий - в среднем 21\%, у больших предприятий - чуть меньше 20\%. В 2015-2017 годах существенных изменений в суммарном объеме производства фотоники (в денежном исчислении) в отрасли не произошло (имел место неболь- шой рост, в основном - из-за роста стоимости импортных комплектующих).

Более 90\% всех моделей гражданской продукции фотоники, предлагаемых сегодня российскими производителями,- это изделия малых предприятий. Именно они формируют внутренний рынок. Большим предприятиям принадлежит основная доля в общем объеме производ-

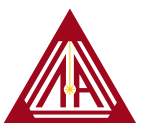
Лазерная ассоциация создана в апреле 1990 г. Это неправительственная и некоммерческая организация, действующая на территории стран СНГ.

В Ассоциацию за 28 лет вступило более 430 коллективных членов и около 600 персональных.

Члены ЛАС выпускают 90\% отечественной лазерной продукции и публикуют 70\% всех научных статей по лазерной тематике на русском языке.

Главная задача ЛАС - помощь своим членам в следующих областях:

- информационное обеспечение работ;

- анализ и экспертиза, консалтинг;

- организация сотрудничества, в т.ч. международного;

- повышение квалификации;

- развитие инновационной деятельности;

- взаимодействие с органами государственной власти.

ЛАС - активно действующая коммуникационная площадка (бюллетень "Лазер-Информ", журнал "Фотоника", ежегодная выставка "Фотоника. Мир лазеров и оптики" и зарубежные презентации, каталоги отечественной лазерной техники, Коллегия национальных экспертов стран СНГ по лазерам и лазерной технике, техплатформа "Фотоника", региональные центры и др.)

С 2015 г. российская часть ЛАС - это ТП «Фотоника".

Puc. 8. Лазерная ассоциация 


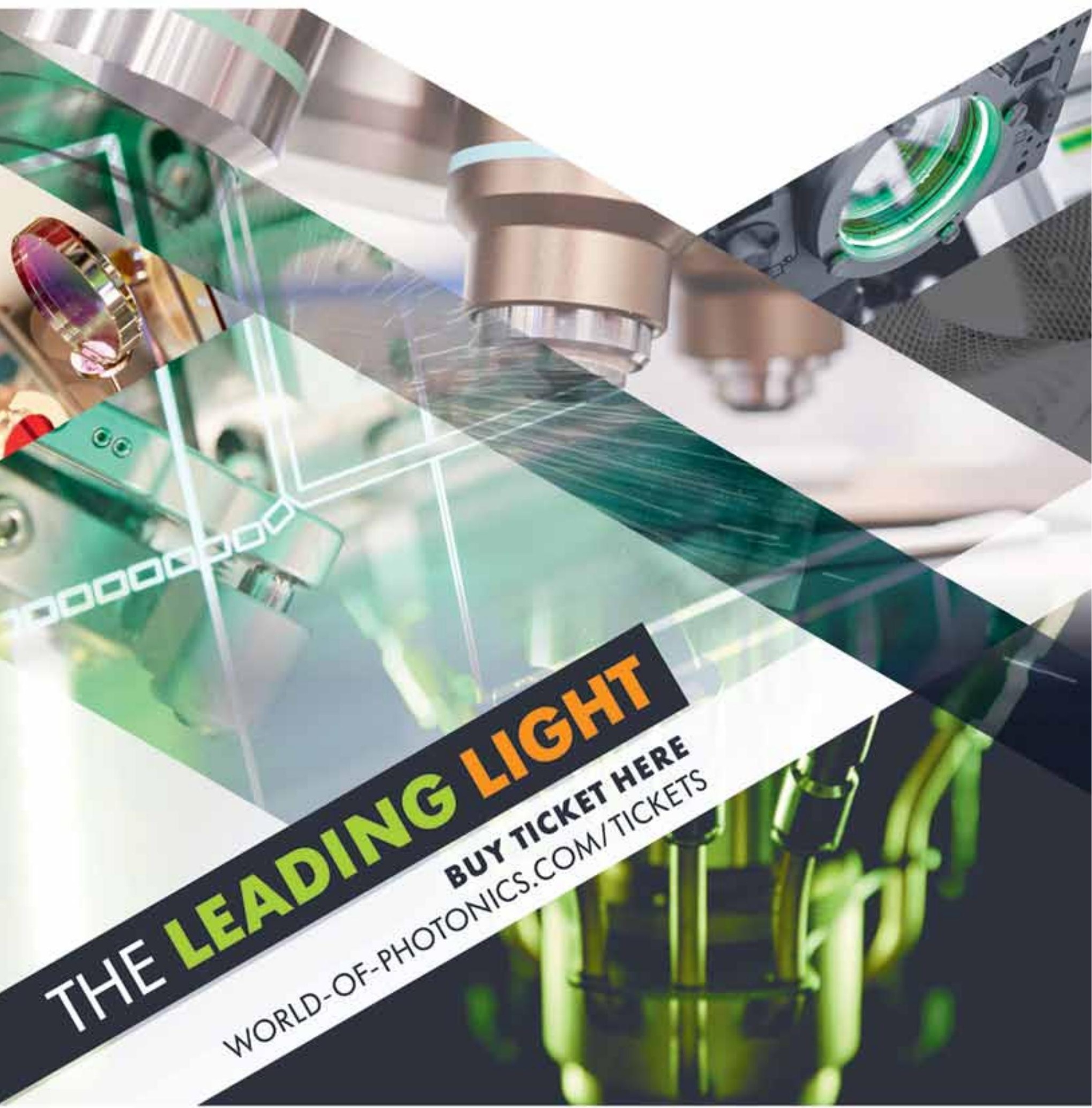

JUNE 24-27, 2019, MESSE MONCHEN

24th International Trade Fair and Congress for Photonics Components, Systems and Applications 


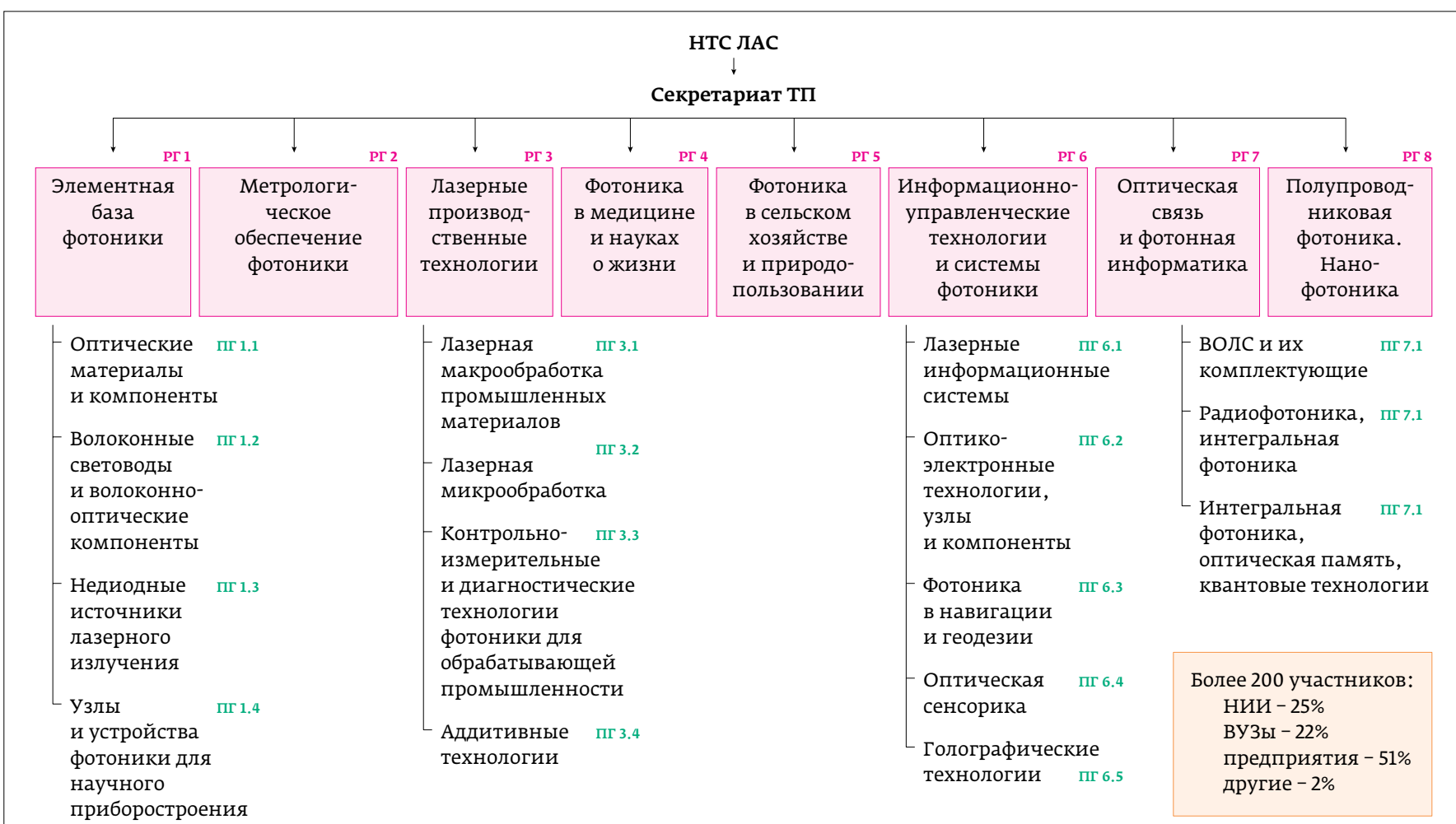

Puc. 9. Структура технологической платформы «Фотоника» (координатор ТП - Лазерная ассоциация)

ства, но они много работают по гособоронзаказу, там другая продукция и другие цены. Открытый рынок фотоники в России создается малыми предприятиями . Единой организационноуправленческой структуры в российской фотонике нет. Как самостоятельная отрасль и единый субъект промышленной политики фотоника в России не существует. Крупнейшим объединением предприятий и организаций этой специализации является Оптический холдинг (АО "Швабе») госкорпорации "Ростех". Имеется также несколько предприятий в составе холдинга "Росэлектроника" той же госкорпорации и объединенные общим руководством своей госкорпорации "лазерные" центры ГК "Росатом", но каждое из этих объединений включает лишь весьма малую долю российских организаций, создающих продукцию фотоники.

Единственными общеотраслевыми структурами являются действующая с 1990 года Лазерная ассоциация и созданная в 2011 году технологическая платформа "Инновационные лазерные, оптические и оптоэлектронные технологии - фотоника", координатором которой является Лазерная ассоциация (рис. 8 и 9). Но это - некоммерческие научно-технические организации, которые своей информационноаналитической, организационной и консультативной деятельностью эффективно содействуют развитию и практическому освоению фотоники в России, но не осуществляют никаких управленческих функций. Обладая большим научнопромышленным потенциалом в области фотоники, Россия сегодня, к сожалению, существенно уступает развитым странам по масштабам практического ее использования, что наносит стране заметный экономический ущерб и замедляет ее модернизацию.

О масштабе потерь можно судить по таким, например, оценкам: 1) использование в машиностроении, на транспорте, в сельхозтехнике и др. технологий локального лазерного упрочнения поверхности стальных деталей с целью повышения износостойкости стальных деталей и соответственно их ресурса может обеспечить экономический эффект порядка 100 млрд руб. (за счет снижения расходов на ремонт, запчасти, борьбу с последствиями аварий, вызванных разрушением изношенных узлов и т.д.); 2) лазерные агротехнологии могут до 1,5 раз поднять урожайность овощных культур и в 2-3 раза удлинить сроки сохранности сорванных плодов 
Развитие

экономики

Новые

производственные

технологии и процессы

в машиностроении

Обработка материалов

и контроль изделий

в электронике

и микроэлектронике

Лазерные

агротехнологии,

обеспечивающие

повышение

урожайности растений,

аквакультур и др.

Лазерные технологии

повышения

продуктивности

животноводства

Солнечная энергетика

Развитие

информационных

технологий,

цифровизация

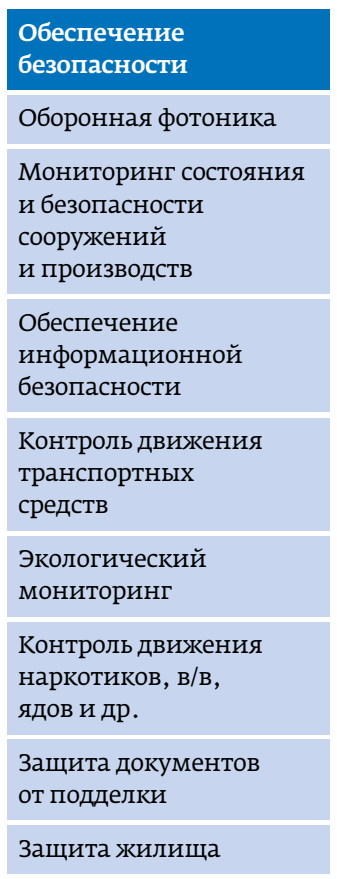

Развитие обеспечения

граждан социальными благами

Медицина - новые методы диагностики и лечения заболеваний, в т. ч. телемедицина

Обеспечение связи, доступа в Интернет, наличия телекоммуникаций

Обеспечение транспортными услугами

Экологический мониторинг

Экономичное освещение

Безналичные

финансовые операции

Развитие науки
и образования
Новые методы
исследований, новая
научная аппаратура
Исследование вещества
в экстремальных
состояниях
Развитие
дистанционных форм
образования
Использование при
обучении методик
виртуальной
реальности

Обеспечение доступа

к культурным

ценностям

Голографические музеи

Дисплеи высокой

четкости

Электронные

библиотеки,

музыкальные

и видео-архивы

с удаленным доступом

Кинотеатры

с лазерными

RGB-проекторами

Возможность

высококачественной

трансляции концертов,

спектаклей и т. п.

Рис. 10. Задачи социально-экономического развития, дяя решений которых необходимы технологии фотоники

(ягоды, яблоки и др.) без принятия каких-либо дополнительных специальных мер, они незаменимы в органическом земледелии; 3) оптоволоконная сенсорика может обеспечить постоянный и не требующий энергетики и трудозатрат контроль состояния всех ответственных сооружений мосты, нефтехранилища, башни, трубопроводы и др.- экономя многомиллионные средства, затрачиваемые на ремонтно-восстановительные работы и устранение последствий техногенных катастроф.

Причинами недоиспользования потенциала фотоники в России являются, во-первых, слабый спрос на инновации в отечественной экономике, не позволяющий отечественной фотонике развиваться за счет чисто рыночных факторов, и, во-вторых, наличие ряда проблем у предприятий и организаций, занятых созданием технологий и оборудования фотоники - как специфических, обусловленных конкретным состоянием дел в том или ином секторе российской фотоники и ее применений, так и общеотраслевых, связанных с отношением ФОИВ к фотонике как второстепенной отрасли (по сравнению, например, с нанотехнологиями) и общим уровнем поддержки инновационной деятельности в стране.
Специфические трудности носят, как правило, технический характер (отсутствие каких-то комплектующих изделий или материалов, недостаточная развитость необходимых технологий и др.), и практически всегда они могут быть при соответствующей поддержке преодолены усилиями конкретных заинтересованных предприятий (организаций), но только после решения системных общеотраслевых проблем. Такие проблемы требуют для своего преодоления участия государства.

Проведенные в 2015 и 2018 годах Лазерной ассоциацией опросы российских предприятий и организаций, работающих в области фотоники, выявили наиболее важные проблемы, которые следует считать общеотраслевыми:

- отсутствие фотоники в официальном перечне приоритетных направлений развития науки, технологий и техники в России и списке критических технологий, что формально запрещает прямую бюджетную поддержку проектов по фотонике и делает эту тематику втростепенной для органов исполнительной власти, отвечающих за инновационную активность, особенно в регионах; 
- слабый спрос на оборудование, реализующее технологии фотоники, в отраслях реального сектора экономики, что обусловлено как финансовой слабостью большинства предприятий, так и отсутствием в стране ясно сформулированной промышленной политики, на которую можно было бы ориентироваться разработчикам инноваций, а также недостаточной осведомленностью руководителей и специалистов о реальных возможностях современной фотоники и ее роли в технической инфраструктуре индустриально развитой страны,

- обусловленное отсутствием программы освоения технологий фотоники в стране отсутствие целевой госпрограммы развития отрасли, в рамках которой могли бы получить поддержку приоритетные для страны работы в области фотоники - в частности, по элементной базе, импортозамещению, по перспективным технологиям, подготовке кадров и др. ;

- отсутствие нормативных документов, предусматривающих и регламентирующих использование технологий фотоники в промышленности, сельском хозяйстве, медицине и др. отраслях, что мешает практическому освоению этих технологий в стране.

- отсутствие координации в поддержке проектов НИОКР по фотонике и ее применениям различными институтами развития, отсутствие гласного анализа использования результатов таких проектов в интересах отечественной экономики.

А еще три отмеченные проблемы характерны для всего отечественного хай-тека, не только для фотоники: 1) отсутствие у предприятий отрасли возможности получать долговременные кредиты под разумный с точки зрения реальной доходности производства лазерно-оптической техники процент; 2) чрезмерная налоговая нагрузка на предприятия и организации, создающие инновационную продукцию, в т. ч. продукцию фотоники; 3) наличие труднопреодолимых препятствий для участия малых предприятий в реализации госзаказа и программ инновационного развития госкорпораций.

Фотоника, как уже отмечалось, является сегодня одним из основных локомотивов инновационного развития экономики. Технологии фотоники играют определяющую роль в переходе к информационному обществу, цифровой экономике, расширению доступной каждому человеку культурной среды, обеспечению мобильности и доступа к информационно-образовательным ресурсам. Эти технологии активно используются в задачах реиндустриализации и социально-экономического развития общества. Нельзя не упомянуть и о важнейшей роли фотоники в обеспечении безопасности - человека, жилища, окружающей среды, страны в целом. В табл. на рис. 10 перечислены указанные в действующей Концепции долгосрочного социально-экономического развития РФ основные группы таких задач и выделены те из них, которые решаются сегодня с использованием технологий фотоники. Оборудование фотоники, которое позволяет реализовать эти технологии, делится на следующие основные группы:

- лазерное оборудование для обработки промышленных материалов, обеспечивающее существенное расширение технологических возможностей предприятий и выбора технических решений, обеспечивающее гибкость и экологическую безопасность производств, конкурентоспособность выпускаемой продукции на мировом рынке;

- лазерно-оптические аппараты и инструменты для медицины, позволяющие существенно более эффективно диагностировать и лечить широкий круг заболеваний, в т. ч. сделать лечение ряда болезней амбулаторной процедурой, успешно бороться с рядом ранее неизлечимых заболеваний (онкология, офтальмология, дерматология, кардиология, гинекология, нейрохирургия и др.), ставшие основными для исследований в области наук о жизни - биофотоники, геномики и др.;

- лазерные информационно-управляющие системы, обеспечивающие бесконтактный дистанционный экологический мониторинг, контроль ландшафтов, акваторий, структуры и состояния поверхностей объектов, реализующие техническое зрение, осуществляющие навигацию, целеуказание, наведение, точную локацию движущихся объектов и др. - эти системы сегодня по-существу не имеют альтернатив;

- устройства фотоники для записи, хранения, обработки и воспроизведения информации, единственно возможные для обработки в реальном времени сверхбольших объемов информации, Переход в информатике к широкому использованию фотоники ожидается в течение 5-7 лет, и возможность производить вышеуказанное оборудование является критически важной для страны; 
- оборудование оптоволоконной связи (волокно, лазерные передатчики и усилители, приемники, мультиплексоры, транспондеры и др.) используется практически повсеместно и непрерывно совершенствуется в результате постоянно растущей потребности в объемах и скорости передачи информации. Возможность производить ключевые элементы такого оборудования определяет не только технологическую независимость государства в части систем связи, но и безопасность пользования такими системами при необходимости передать закрытую информацию;

- оборудование фотовольтаики (солнечная энергетика), остро необходимое для энергосбережения, снижения нагрузки на окружающую среду, обусловленной выбросами тепловых электростанций, для сохранения истощающихся запасов углеводородов. Эффективные солнечные батареи могут существенно улучшить качество жизни миллионов россиян, живущих вне доступа к централизованному электроснабжению, переход к использованию светодиодных систем позволяет существенно (в разы) снизить расходы электроэнергии на освещение;

- лазерное оборудование для реализации агротехнологий, ветеринарной медицины, улучшения природопользования, позволяющее при очень малых затратах существенно увеличить эффективность сельхозпроизводства и уменьшить загрязненность пашен, пастбищ и, соответственно, продуктов питания пестицидами, антибиотиками и др. Лазерные агротехнологии чрезвычайно перспективны для реализации "органического" земледелия.

Особое место в этом перечне занимает оборонная фотоника, без которой невозможны современная армия и системы обеспечения безопасности. Организация разработки и производства такого оборудования в объемах, необходимых для развития отечественной экономики и обеспечения безопасности, является, на наш взгляд, важнейшей задачей государства.

Во второй части обзора будут рассмотрены задачи, стоящие перед отраслью. Их решение позволит использовать высокий потенциал, заложенный в фотонике. 